\title{
ЦИФРОВАЯ ТРАНСФОРМАЦИЯ В КОНЦЕПЦИИ ЭКОНОМИЧЕСКОЙ БЕЗОПАСНОСТИ
}

\author{
(c) 2019 Чечин Олег Павлович \\ кандидат экономических наук, доцент \\ Самарский государственный экономический университет, Россия, Самара \\ E-mail: cheche18@rambler.ru
}

Цифровая экономика в современном мире набирает обороты и становится неотъемлемой частью нашей жизни. Тенденции цифровой трансформации экономики формируют вызовы и соответствующие конкретные угрозы и риски развития социально-экономических систем.

В статье дан обзор возможным вызовам и угрозам обществу и организациям в рамках развития цифровой трансформации экономики. А также определены основные стратегические задачи цифровой трансформации в концепции экономической безопасности.

Ключевые слова: экономическая безопасность, стратегическое развитие, цифровая экономика, инновации, цифровая трансформация, управление рисками.

Цифровая экономика в современном мире набирает обороты и становится неотъемлемой частью нашей жизни. В России приняты соответствующие государственные решения в рамках: Указа Президента Российской Федерации от 9 мая 2017 г. № 203 «О Стратегии развития информационного общества в Российской Федерации на 2017-2030 годы»; Утверждена программа «Цифровая экономика Российской Федерации» распоряжением Правительства Российской Федерации от 28 июля 2017 г. № 1632-р; Указа Президента Российской Федерации от 07.05.2018 № 204 «О национальных целях и стратегических задачах развития Российской Федерации на период до 2024 года». Это говорит о значимости цифровизации общества и необходимости постановки задач в развитии данного направления деятельности [5].

Тенденции цифровой трансформации экономики формируют вызовы и соответствующие конкретные угрозы развития социальноэкономических систем. Например: 1) связанные с потенциальным сокращением рабочих мест могут спровоцировать социальную и экономическую нестабильность; 2) усиление разрыва в уровнях технологического развития между странами, а также между различными экономическими группами в зависимости от доступа и эффективности использования интеллектуальных ресурсов [3]; 3) рост вероятности возникновения техногенных катастроф, неспособность человека лидировать в принятии управленческих решений по сравнению с интеллектуальными системами [2]; 4) экологические риски требуют создания системы мониторинга происходящих технологических изменений, их влияния на экологию, обеспечения противодействия и защиту от климатических изменений; 5) риски усиления терроризма, сложность обеспечения конфиденциальности информации, угроза новых моделей кибервооружения.

В Программе развития цифровой экономики в Российской Федерации до 2035 года понятие «цифровая трансформация экономики» определено, как: изменение модели управления экономикой от программно-целевой к программнопрогностической; смена экономического уклада, изменение традиционных рынков, социальных отношений, государственного управления, связанная с проникновением в них цифровых технологий; принципиальное изменение основного источника добавленной стоимости и структуры экономики за счет формирования более эффективных экономических процессов, обеспеченных цифровыми инфраструктурами; переход функции лидирующего механизма развития экономики к институтам, основанным на цифровых моделях и процессах [8].

Цифровая трансформация - неоднозначная парадигма общественного развития, при всех ее положительных эффектах необходимо уметь прогнозировать, выявлять и управлять негативными тенденциями, вызовами и угрозами. Так, в мире в среднем $64 \%$ топ-менеджеров рассматриваю вопросы цифровой трансформации своих компаний, но $24 \%$ не делают и этого. В России 
картина такая: большая часть (62\%) руководителей не обращают внимания на проблемы цифровой трансформации, и только $35 \%$ поступают так, как большинство топ-менеджеров в мире, т.е. включают их в круг рассматриваемых вопросов. Что же касается компаний в целом, то их реагирование на цифровую трансформацию заметно консервативней: 43\% (в России 52\%) компаний не признают угрозы со стороны цифровой трансформации или признают, но не реагируют на них [1].

Особенности реагирования российского бизнеса на цифровую трансформацию эксперты объясняют так: нефтегазовый сектор, который дает более трети бюджетных денег, а также играет значимую роль в российской экономике в целом, не является лидером в направлении цифровизации; около двух третей ВВП страны обеспечивают госкомпании, ИТ-стратегии которых больше зависят от регуляторов, нежели от бизнес-показателей; Россия по-прежнему находится в позиции догоняющей страны по отношению к странам с развитыми экономиками, что позволяет ей выжидать более взвешенных шагов в цифровизации; экономический кризис не способствует инвестициям в инновации.

Прогнозы специалистов говорят, что в ближайшие пять лет $40 \%$ компаний исчезнут с рынка. Не зря последние несколько лет идут спекуляции на тему оперативности реагирования (agility) бизнеса на изменение условий его развития и даже существования. Хотя этот прогноз распространяется на все виды бизнеса, в первую очередь, поймать «волну цифровизации» должны постараться представители направления высоких технологий. Но для этого требуются соответствующие персонал, оборудование, компетенции, знания. Они весьма специфичны и большинство компаний ими не обладают. Следовательно, необходимо привлечение для успешной цифровой трансформации сторонних специализированных сервисных операторов, которые, вследствие этого, начинают играть ключевую роль в дальнейшем успешном развитии российской экономики. Достижение такого состояния социально-экономических систем возможно исключительно посредством цифровой трансформации, основными драйверами которой на сегодняшний день являются новые продукты и сервисы, новейшие информационные и управленческие технологии, инновационные бизнес-модели, отраслевые цифровые платформы. При этом цифровая трансформация неразрывно связана с глобальной тенденцией сервисизации экономики, с одной стороны, выступая ее технологической основой, а с другой - порождая новый сегмент сферы услуг цифровые услуги, который развивается опережающими темпами.

Вопросы обеспечения экономической безопасности в условиях реализации социальных, экономических, политических процессов и явлений набирают все большую актуальность. Направления современной деятельности являются источниками вновь создаваемых вызовов и угроз, что, требует разработки новых принципов их минимизации. Практика показывает, что экономическая безопасность является приоритетным условием стабильности и достижения результатов в развитии государства, региона и отдельно взятого человека. Таким образом, это набор экономических, политических, правовых инструментов, которые способствуют защите жизненно важных интересов общества, государства, предприятия и личности.

Приоритетной задачей обеспечения экономической безопасности, особенно в быстро меняющихся внешних условиях, является прогнозирование угроз и рисков, к реализации которых необходимо готовиться на постоянной основе. Всеобъемлющим глобальным вызовом является тенденция эволюции цифрового мира.

Современные цифровые технологии занимают лидирующее место в развитии науки, техники, экономики и управления во всем мире [4]. Эффективное управление данными как ключевым ресурсом цифровой экономики является залогом успеха в любом виде хозяйственной деятельности, а монопольное обладание определенными данными зачастую оказывается решающим преимуществом в конкурентной борьбе. Так как в современном мире основная деятельность экономических агентов часто связана с применением цифровых технологий, выполнение операций с различного рода данными, нахождение в глобальном цифровом пространстве [2] с одной стороны, дает дополнительные возможности для получения экономического эффекта, с другой стороны, создает определенные риски для дальнейшего развития.

Глубокие изменения, вызванные использованием цифровых технологий, значительно расширили масштабы проблем при обеспечении экономической безопасности. Эффектив- 
ное управление рисками в условиях развития цифрового пространства имеет большое значение для реализации экономических и социальных преимуществ цифровой экономики. Формирование доверия в новых условиях взаимодействия, основой которых являются цифровые технологии - важное условие социальноэкономического развития. Взаимодействие власти, бизнеса, общественных организаций в вопросах цифровой безопасности играет ключевую роль в поддержке условий для укрепления основ совместной деятельности в такой ситуации. Несмотря на значительное внимание к проблемам развития цифровой экономики среди множества экспертов, вопросы влияния цифровых технологий на экономическую безопасность разработаны достаточно слабо.

Существенные изменения в социальноэкономических отношениях, способах производства сопровождаются целым набором особенностей, характерных для цифровой экономики и проявляющихся в следующих моментах:

1. Наличие интеллектуальных активов, которые используются для повышения экономической эффективности.

2. Повышение значимости данных в хозяйственной деятельности.

3. Приоритетной организационной структурой становится сеть, а не иерархия.

4. Основным источником информации и связи является глобальная сеть.

5. Основной задачей управления является обеспечение социально-экономической безопасности.

Движение в сторону более тесного взаимодействия с потребителем можно считать ответной реакцией компаний на изменения в бизнессреде, повышение уровня непредсказуемости рынков и рост уровня рисков.

В последние годы цифровые технологии, включая интернет, стали основой функционирования экономики, ключевым фактором развития во всех ее секторах [5]. Эффективное функционирование экономики стало зависимым от цифровой среды. При этом все чаще заметно растущее число неопределенностей, присущих цифровому пространству. Цифровые угрозы стали масштабней, что зачастую приводит к значительным финансовым, репутационным, временным потерям. В отчете ВЭФ по глобальным рискам (The Global Risks Report, 2018) такие общемировые угрозы, как киберпреступность и кража данных расположены на третьем и четвертом месте по их значимости. Вызовы, связанные с цифровыми технологиями, в той или иной степени обозначены в планах развития большинства государств, которые стремятся решать социально-экономические вопросы и снижать риски цифровизации путем разработки и реализации стратегий безопасности в цифровом пространстве.

Безопасность цифровых систем является актуальной проблемой для экономики и общества в целом и одним из ключевых направлений управления цифровой экономикой и требует адекватных мер защиты всех участников.

Исследованию проблем, связанных с развитием цифровых технологий, посвящено достаточно большое число работ отечественных и зарубежных исследователей [4]. Так, исследована трансформация экономики при внедрении цифровых технологий. Обсуждается влияние государства на развитие цифрового общества. Рассмотрены вопросы доверия и частной собственности при информационных взаимодействиях. Изучены вопросы обработки больших баз данных. Исследованы частные последствия применения кибератак. При этом стоит отметить многогранность изменений, вызванных цифровизацией, что породило значительное число тем для анализа, включающих как изучение системных изменений в экономике (например, трансформация рынка труда и связанная с этим проблема безработицы или появление крипто-валют и связанные с ними спекуляции), так и прикладные исследования, к примеру, в области использования определенных программных продуктов в рамках деятельности отдельных предприятий.

Несмотря на то, что субъекты экономики все больше ощущают влияние цифровой среды на собственную деятельность, зачастую этот вопрос рассматривается ими исключительно с технической точки зрения. Становится понятно, что решение о переходе к цифровой экономике должно быть, прежде всего, неотъемлемой частью принятия экономических и социальных решений для того, чтобы все участники могли в полной мере воспользоваться возможностями, предоставляемыми цифровой средой.

Сегодня цифровая экономика опирается на сложную экосистему взаимосвязанных информационных и коммуникационных технологий, 
основанную на обработке «больших данных», обеспечиваемых сложным аналитическим инструментарием. В такой многоуровневой взаимозависимой структуре существуют риски, представляющие собой проблему многостороннего характера. То, что происходит в малом бизнесе, может оказать влияние на крупный бизнес и всех участников цепочки создания стоимости. Верно и обратное: системный сбой в цифровой системе страны поставит под угрозу существование отдельных предприятий, банков, организаций государственного сектора.

В этой среде данные стали основным активом. Широкое использование больших объемов данных и аналитики для значительного улучшения или стимулирования разработки новых продуктов, процессов, организационных методов и создания рынков стало основой для формирования концепции «инноваций, основанных на данных» («data-driven innovation, DDI») [7].

C одной стороны, данный подход позволяет повысить эффективность различных операций, начиная от оптимизации и реинжиниринга, улучшения отношений с клиентами и развития новых рынков и до решения более глобальных социальных и экологических проблем. Эффективность развития в таких условиях напрямую зависит от открытости и взаимосвязанности цифровой среды, от способности легко, гибко и дешево перемещать данные среди потенциально неограниченного числа участников.

С другой стороны, интенсивный обмен и использование больших потоков данных снижают степень конфиденциальности используемой информации и способствуют созданию ряда цифровых угроз. Идея о том, что по соображениям безопасности система должна оставаться закрытой по умолчанию, относится к прошлому, когда информационные технологии не были разработаны для обеспечения совместимости, а их вклад в экономический и социальный прогресс меньше зависел от свободного потока данных. Закрытие этих систем уже невозможно без подрыва связанных с этим экономических и социальных эффектов и, поэтому, в результате приведет лишь к иллюзии безопасности.

Все больше небольших и крупных компаний, таких как интернет-магазины, поставщики интернет-услуг, банки [6] и государственные организации собирают огромное количество персональных данных. Собирая и анализируя большие объемы данных, компании могут про- гнозировать совокупные тенденции, такие как колебания спроса, а также индивидуальные предпочтения клиентов, а благодаря наблюдению за индивидуальным поведением, фирмы совершенствуют свои продукты и услуги. Однако эта способность профилировать и отправлять целевые сообщения и маркетинговые предложения для отдельных лиц также может иметь неблагоприятные последствия: некоторые потребители могут возражать против того, чтобы их активность в сети исследовалась и анализировалась. Широкое внедрение цифровых технологий, в том числе мобильных устройств, и рост социальных сетей коренным образом изменили роль отдельных пользователей. Сами пользователи создают, публикуют и обмениваются информацией, используя различные цифровые платформы, в том числе социальные сети, сайты для обмена фотографиями, рейтинговые системы, создавая при этом определенные угрозы личной безопасности, поскольку у них зачастую отсутствуют механизмы контроля над тем, что другие пользователи могут делать с этим контентом. Это порождает сложные вопросы о том, как государство должно реагировать на новую роль граждан как создателей и распространителей контента и личных данных.

В последние годы крупные и малые организации подвергаются более частым и серьезным угрозам в цифровой среде, что влияет на их экономическую безопасность. С экономической точки зрения подобные угрозы могут влиять на репутацию организаций, финансовую составляющую, нанося ущерб их конкурентоспособности, подрывая их усилия по инновациям и позиции на рынке. Такие угрозы могут нарушить доступность, целостность или конфиденциальность информационных систем, на которых основывается экономическая деятельность.

Адекватным ответом на обозначенные вызовы цифрового общества становятся изменения в структуре и подходах к управлению экономическими системами разного уровня. На первый план в таких изменениях выходят горизонтальные команды, направленные на получение результатов. Это требует перехода от замкнутых, излишне бюрократизированных структур к открытым организациям, образующим сеть. Такие организации являются гибридными формами экономической деятельности с гибкими связями, которые устанавливаются и пересматриваются по мере необходимости. 
Приоритетными вопросами в таких сетевых структурах становятся вопросы об управлении ресурсами в реальном времени и координации деятельности участников сети. В рамках развития «долевой экономики» данный подход реализуется за счет цифровых платформ, с помощью которых участники могут координироваться с целью более эффективного использования ресурсов. Подобные инструменты позволяют более эффективно использовать ресурсы, повышая их доступность, снижая нагрузку на окружающую среду. Инновации, основанные на данных (DDI) способствуют социально-экономическому развитию, помогают решать усложняющиеся социально-экономические вопросы. В такой цифровой среде, основанной на передаче данных, также усиливаются вопросы обеспечения цифровой конфиденциальности, экономической безопасности. В большой степени экономическое развитие достигается за счет открытого обмена данными, что, в свою очередь, увеличивает сложность обеспечения кибербезопасности и управления рисками в цифровой среде. При этом риски, связанные с цифровизацией среды, должны рассматриваться в социальной и экономической плоскости, а не только с технической точки зрения. Отдельного внимания заслуживает поддержка бизнеса в снижении рисков [6] от использования цифровых технологий в экономической деятельности. Зачастую предприятия сталкиваются с проблемами в цифровой среде, имея слабые возможности по обеспечению собственной экономической безопасности в новых условиях. Такая ситуация требует новых подходов к управлению рисками, включая рыночные инструменты.

Изучение тенденций, факторов и условий, в которых отечественная социально- экономическая система входит в цифровую глобальную систему, позволяет утверждать, что набирающий обороты мировой тренд цифровой трансформации далеко неоднозначен в своем влиянии на общество. Это требует применения соответствующей методологии и инструментария по выявлению и управлению рисками и угрозами цифровой трансформации социально экономических систем для получения в полной мере ожидаемых положительных эффектов цифровой экономики. Для этого, инициируемые в отечественных социально-экономических системах процессы цифровой трансформации, в первую очередь, должны иметь под собой научно-обоснованную методологическую инструментальную базу.

Таким образом, основные стратегические задачи цифровой трансформации в концепции экономической безопасности можно сформулировать как: создание инновационного развития системы обеспечения информационной безопасности, отрасли информационных технологий и электронной промышленности; создание и внедрение информационных технологий, изначально устойчивых к различным видам угроз; проведение научных исследований и осуществление опытных разработок в целях создания перспективных информационных технологий и средств; повышение защищенности информационной инфраструктуры и устойчивости ее функционирования, развитие механизмов обнаружения и предупреждения информационных угроз и ликвидации последствий их проявления; совершенствование методов и способов производства и безопасного применения продукции, оказания услуг на основе информационных технологий с использованием разработок, удовлетворяющих требованиям безопасности.

\section{Библиографический список}

1. Грибанов Ю.И. Цифровизация национальной экономики: вызовы и ответственность бизнеса (государственно-частное партнерство) / Динамика взаимоотношений различных областей науки в современных условиях: сб. ст. по матер. междунар. науч.-практ. конф. В 3 ч. Ч. 1. Стерлитамак: АМИ, 2018. С. 4250.

2. Коновалова М.Е., Михайлов А.М., Кузьмина О.Ю. Прогнозирование развития фондовых рынков в условиях становления цифровой экономики //Вестник Самарского государственного экономического университета. 2018. № 4 (162). С. 9-15.

3. Коновалова М.Е., Кузьмина О.Ю., Михайлов А.М. Формирование человеческого капитала на основе информации и знаний //Экономика и управление собственностью. 2018. № 1. С. 57-61. 
4. Копылова А.А., Михайлов А.М. Знания и информация как основные ресурсы цифровой экономики /Глобализация и региональное развитие в XX1 в.: векторы развития, вызовы, инновации. Сборник научных статей Всероссийской (с международным участием) научно-практической конференции магистрантов, аспирантов и адъюнктов. 2019.С. 304-308.

5. Михайлов А.М., Андреев П.А. Формирование условий для развития цифровой экономики //Экономика и социология. 2017. № 36.С. 19-21.

6. Михайлов А.М., Патрин С. М. Управление рисками розничного банка //Вестник Самарского государственного экономического университета. 2015. № 5 (127). С. 9-104-110.

7. Попов E. В., Семячков К.А. Компаративный анализ стратегических аспектов развития цифровой экономики // Вестник Пермского университета.- 2018.- Т. 13.- № 1.- C. 19-36.- (Экономика).- DOI: doi 10.17072/1994-9960-2018-1-19-36.2.

8. Программа развития цифровой экономики в Российской Федерации до 2035 года. Электронный ресурс. URL: http://spkurdvumov.ru/uploads/2017/05/strategy.pdf. 